\title{
CURVATURA DE BAMBU LAMINADO COLADO
}

\author{
Marco Antonio dos Reis Pereira \\ Universidade Estadual Paulista- Unesp \\ pereira@feb.unesp.br \\ Bruno Perazzelli Faria Ramos \\ Universidade Estadual Paulista- Unesp \\ bperazzelli@hotmail.com
}

Resumo: O presente trabalho trata de uma revisão de literatura, utilizando metodologia de revisão assistemática, sobre curvatura de bambu laminado colado, espécies, seus métodos produtivos e uso para fabricação de mobiliário. Pautada na busca por materiais e métodos produtivos mais sustentáveis, esta revisão, que consiste na primeira etapa de uma dissertação de mestrado em design, aborda tópicos que vão desde as características gerais do bambu, a escolha das espécies mais adequadas para o bambu laminado colado (BLC), o processamento do bambu em ripas laminadas, a confecção do BLC e sua curvatura. Após a revisão, foi possível identificar o grande potencial do bambu como matéria-prima e as inúmeras possibilidades do BLC curvo, porém, também comprovou-se a escassez de literatura sobre métodos de curvatura de BLC, tanto em publicações e pesquisas nacionais como em internacionais na língua inglesa. A maior parte das informações encontradas trata das espécies de bambu e suas características, assim como ensaios físicos e mecânicos para suas propriedades de resistência, enquanto que suas aplicações industriais são pouco exploradas e as técnicas de processamento pouco difundidas. Portanto, tal carência de informações sobre o BLC curvo confirma a necessidade de pesquisa e desenvolvimento em nosso país neste tema, demandando a continuidade de estudos para o bambu laminado colado curvo e suas diversas possibilidades de aplicação, especialmente voltadas para o mobiliário.

Palavras-chave: design, mobiliário, curvatura de bambu laminado colado.

\footnotetext{
Abstract: This paper is a literature review, using non-systematic review methodology, about glued laminated bamboo bending, its production methods and use for furniture manufacturing. Guided by the search for more sustainable materials and production methods, this review, which is the first stage of a master's thesis in design, covers topics ranging from the general characteristics of bamboo, the choice of the most suitable species
} 
for Glue Laminated Bamboo (GLB), the processing of the bamboo in laminated slats, the manufacture of the GLB and its bending. After the review, it was possible to identify the great potential of bamboo as a raw material and the numerous possibilities of bend $G L B$, however, also proved the lack of literature on methods of GLB bending, either in the national, or international, researches and publications. Most of the information found is about the bamboo species and their characteristics, as well as physical and mechanical tests and strength properties, while their industrial applications are little explored and processing techniques are poorly disseminated. Therefore, this lack of information on the curved GLB confirms the need for research and development in our country in this subject, demanding the continuity of studies for curved glued laminated bamboo and its many application possibilities, especially aimed at the furniture

Keywords: design, furniture, glued laminated bamboo bending

\section{INTRODUÇÃO}

Nas últimas décadas, e cada vez mais, a busca pela sustentabilidade tem instigado a pesquisa nas mais diversas áreas do conhecimento em prol do desenvolvimento de soluções mais sustentáveis para os atuais processos produtivos e ciclo de vida dos produtos, e o Designer, elemento determinante no desenvolvimento destes produtos e processos, tem função vital como agente consciente e transformador tanto do meio em que se vive quanto da cultura que é perpetuada.

Dentre os diversos pontos de atuação do Designer no processo produtivo, têmse a busca por materiais alternativos como um fator primordial a ser pensado, e a pesquisa por novos processos produtivos como o catalizador da ação que culmina no desenvolvimento de produtos. O trabalho é focado em dois pontos: a) na pesquisa da matéria-prima bambu como material alternativo e b) técnicas de curvatura do laminado de bambu colado como processos produtivos a serem utilizados para fabricação de móveis.

O bambu tem recebido considerável atenção como um dos materiais alternativos mais sustentáveis. Esta planta é uma das maiores fontes renováveis de biomassa no planeta, sendo um substituto para madeira, e mostrando desmembramentos positivos em relação ao meio ambiente. O bambu tem potencial para ser uma verdadeira fonte sustentável, e integrar todos os pilares da sustentabilidade: ambiental, social, econômico e cultural (REUBENS, 2010).

Observando-se globalmente o uso do bambu, veem-se duas direções principais. A mais usada, e convencional, é do bambu em sua forma in natura, que é muito útil e pode ser aplicada desde a fabricação de utensílios domésticos até na construção civil. O lado negativo é que o bambu in natura é de difícil padronização devido às suas dimensões irregulares, e também é suscetível a rachaduras durante sua secagem, o que acaba por transformar a geometria do bambu, diminuindo sua capacidade estrutural. O outro tipo de uso para o bambu é na forma processada, ou industrializada, a qual pode envolver a divisão do bambu até seus elementos fibrosos, e posteriormente pode-se obter novas formas geométricas, como requerido por normas, após tais processamentos o bambu adquire uma aparência completamente distinta do bambu in natura (XIAO; INOUE; PAUDEL, 2008). 
Devido à grande quantidade de fibras presentes no bambu, suas aplicações industriais como contraplacado ou o Strand Woven Bamboo (SWB) apresentam propriedades mecânicas e estéticas competitivas com as madeiras folhosas e até melhores que as madeiras coníferas, considerando-se que o volume de produção anual deve ser maior para o bambu, graças a sua alta taxa produtiva. Generalizando, pode-se chegar a seguinte conclusão: o bambu cresce mais rápido que as madeiras coníferas e tem as propriedades das madeiras folhosas (VAN DER LUGT, 2008). Considerando-se o aumento na demanda e a valorização das matérias-primas ligno-celulósicas e a diminuição de florestas nativas por todo o planeta, os materiais a base de bambu podem servir como uma alternativa de baixo custo, para amenizar pelo menos em parte a demanda por produtos em madeira oriunda de florestas.

De todas as aplicações do bambu processado, o bambu laminado colado (BLC) é o que apresenta maior potencial, devido à sua solidez e à geometria versátil. O BLC é comparável a outros produtos de madeira como vigas e treliças, e também é comparável a produtos de madeira processada, como laminados colados e folheados (XIAO; INOUE; PAUDEL, 2008). Materiais compostos como o bambu laminado colado e madeira laminada colada se referem a diversas camadas de lâminas de bambu ou madeira, coladas com as fibras paralelas ou direcionadas no mesmo sentido, relata Hidalgo-López (2003).

O BLC curvo pode ser usado para a fabricação de cadeiras, sofás, estantes, gabinetes e mesas, sendo um excelente substituto para a madeira. Apesar de os móveis de bambu laminado serem relativamente novos, o mercado está crescendo rapidamente; atualmente, a China é o único local onde são produzidos, ainda em escala mediana, mas existe muito potencial, particularmente em se tratando de exportações para a América do Norte e Europa (BINYUAN; JINGYAN, 2001).

Considerando-se as excelentes propriedades do BLC curvo e suas inúmeras aplicações, assim como o apelo do bambu como material sustentável, realizou-se uma revisão de literatura em fontes nacionais e internacionais para embasar o desenvolvimento de uma metodologia de curvatura do bambu laminado com foco na fabricação de mobiliário.

\subsection{Objetivo}

Realizar uma revisão de literatura acerca dos temas bambu, bambu laminado colado e bambu laminado colado curvo com foco na fabricação de mobiliário.

\subsection{Metodologia}

Realizou-se uma revisão bibliográfica assistemática em livros, teses, dissertações e artigos, tanto nacionais como internacionais, baseada em palavras e frases, sobre curvatura de bambu laminado colado e os temas que cercam este assunto, desde as espécies apropriadas de bambu, suas características, técnicas de processamento e laminação até sua utilização na fabricação e mobiliários. 


\section{DESENVOLVIMENTO}

\subsection{Bambu}

O bambu é uma gramínea arborescente gigante, e como tal, ele pertence à família Gramineae (Poaceae), subfamília Bambusoideae, que é dividida em dois grandes grupos: os bambus herbáceos, e os bambus lenhosos, conhecidos simplesmente como "bambus". Este segundo grupo forma a tribo Bambuseae, que apresenta colmos lenhosos, geralmente ocos e divididos em septos ou diafragmas. Ramificam-se pelos nós e geralmente se multiplicam pelos rizomas que por sua vez geram novos colmos. O florescimento ocorre somente depois de muitos anos, quando a maioria produz sementes e depois morre (HIDALGO-LÓPEZ, 2003).

Devido à alta produtividade anual e à capacidade das plantações de bambu serem estabelecidas em áreas onde as árvores talvez não sobrevivam, o bambu pode ser uma alternativa promissora para se atingir a demanda crescente por matériasprimas, em particular a madeira. Portanto, o bambu pode ter um papel importante como fonte de matéria-prima para suprir a necessidade humana por fibras e madeiras para habitação, revestimento e acabamento interior, móveis, utensílios domésticos e outros produtos duráveis (VAN DER LUGT; VOGTLÄNDER; BREZET, 2009).

Moizés (2007) relata que o uso do bambu no Ocidente é restrito se comparado com a China, Índia e Japão, principalmente por questões culturais, já que no Oriente seu uso no cotidiano é milenar. Em tais países, o uso do bambu não se restringe somente à sua forma in natura, sendo utilizado também para a fabricação de pisos laminados, painéis laminados e derivados. No Brasil, o bambu é utilizado na forma natural (colmos) em estruturas de casas e objetos em geral, vinculados principalmente às tradições indígenas e aos imigrantes orientais.

O Brasil possui aproximadamente $20 \%$ do total de espécies de bambu encontradas em todo o mundo, porém ele não apresenta grandes recursos de bambu, e esta é uma das explicações para o fato de a exploração desta planta no país estar restrita, em sua grande maioria, aos usos tradicionais como balaios, tutores na agricultura e construções provisórias (CARDOSO JUNIOR, 2008).

Apesar das inúmeras espécies e usos possíveis do bambu, é necessário ressaltar o fato de que não existe uma só espécie capaz de abranger todas as aplicações possíveis. O que existe são espécies mais indicadas para um determinado tipo de exploração ou aplicação, pois enquanto algumas são ideais para a produção de brotos comestíveis, outras o são para a fabricação de celulose e papel, e enquanto algumas são insubstituíveis na confecção de artesanatos e móveis, outras são resistentes o suficiente para serem empregadas em qualquer tipo de construção (GRECO; CROMBERG, 2011).

Para a fabricação do bambu laminado colado são necessários bambus de grande porte, com parede espessa, por isso, as espécies mais utilizadas são: Dendrocalamus giganteus, Dendrocalamus latiflorus, Dendrocalamus asper, Guadua angustifolia e Phyllostachys pubescens (MOIZÉS, 2007). Destas espécies, a D. giganteus já possui considerável quantidade de estudos sobre seu cultivo, processamento e laminação, e por isso, foi escolhida como matéria-prima para esta pesquisa.

Segundo os autores Greco e Cromberg (2011), Pereira e Beraldo (2008) e Rao, Rao e Williams (1998), a espécie de bambu $D$. giganteus é originária da Tailândia e conhecida popularmente como bambu gigante ou bambu balde; possui cor verde 
azulada escura, é do tipo entouceirante e de grande porte, sendo considerada uma das maiores bambu do mundo, atingindo alturas de 24 a $40 \mathrm{~m}$; os colmos são extremamente fortes e de parede espessa (entre 1 e $3 \mathrm{~cm}$ ); o diâmetro dos colmos varia entre 10 e $20 \mathrm{~cm}$, enquanto que os internós apresentam entre 40 e $50 \mathrm{~cm}$ de comprimento. A Figura 1 apresenta o bambu da espécie $D$. giganteus.

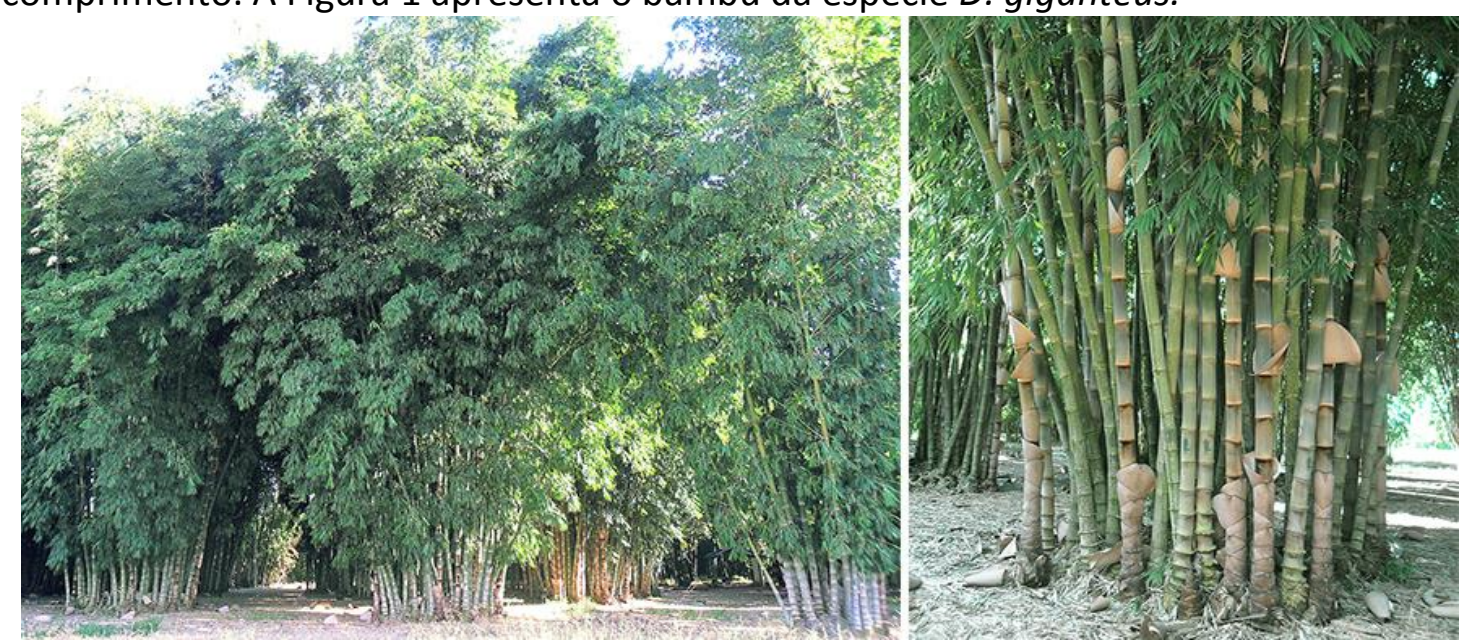

Figura 1 - Dendrocalamus giganteus

Fonte: elaborado pelo autor

\subsection{Bambu Industrializado}

Designers contemporâneos, de diversos países, têm explorado com sucesso o bambu, desenvolvendo produtos inovadores e de alta qualidade. A maioria dos designers tem usado o bambu reconstituído com uma abordagem altamente tecnológica, por meio da qual as conotações negativas associadas aos produtos de bambu in natura, como "rusticidade", "baixo custo", "qualidade ruim", são eliminadas (REUBENS, 2010). Assim, possibilita-se ao mercado vislumbrar os produtos livres destas associações negativas e se abre uma nova gama de oportunidades para os produtos de bambu.

Aplicações de alta tecnologia tem grande demanda nos países desenvolvidos e mercados urbanos, porém, estas aplicações requerem insumos tecnológicos específicos e a maioria destas tecnologias não são disseminadas. Reubens (2010) destaca que inovações relacionadas, por exemplo, às fibras e fios de bambu, fibras de bambu com reforço plástico, painéis de bambu e laminado de bambu, se encaixam dentro destes tipos de tecnologias. Os principais painéis industriais de bambu incluem painéis entrelaçados, de laminados, partículas, fibras, lascas, contraplacados, ondulados, folheados decorativos, piso e compósitos, desenvolvidos principalmente em países orientais, como a China (YUMING; CHAOMAO, 2010).

Existem inúmeras chapas de bambu fabricadas em países como China, Índia, Vietnã, Malásia, Indonésia, Taiwan e Filipinas, sendo que uma dentre as mais utilizadas e encontradas é a de bambu laminado colado.

O BLC pode ser produzido tanto em escala industrial quanto em pequena escala, pois os equipamentos e maquinários utilizados para o processamento bambu e fabricação dos laminados podem ser de pequeno, médio e até grande porte (CARDOSO JUNIOR, 2008). Ultimamente, a fabricação de BLC tem crescido nos países da América 
Latina, como o Equador, Costa Rica e Colômbia, que utilizam, com adaptações, a tecnologia produzida pela Ásia (PEIXOTO, 2010).

Para produção do BLC, o primeiro passo é a obtenção das ripas laminadas, que pode ocorrer pela técnica por corte (folheado) ou por serragem. Com a técnica de corte é possível obter lâminas, ou folhas de bambu, extremamente finas. O termo folheado é comumente aplicado a qualquer tipo de finas camadas ou folhas de madeira, cortadas de uma tora. Segundo Hidalgo-López (2003) e Moizés (2007), o folheado de bambu é usado na fabricação de contraplacados de bambu, composto com outras folhas mais espessas, e com propósitos decorativos para revestimento de madeiras inferiores.

Folheados também podem ser produzidos através do fatiamento de peças de bambu laminado, que para tal, são deixadas de molho em água para amolecer. Os dois processos de folheamento são apresentados na Figura 2.

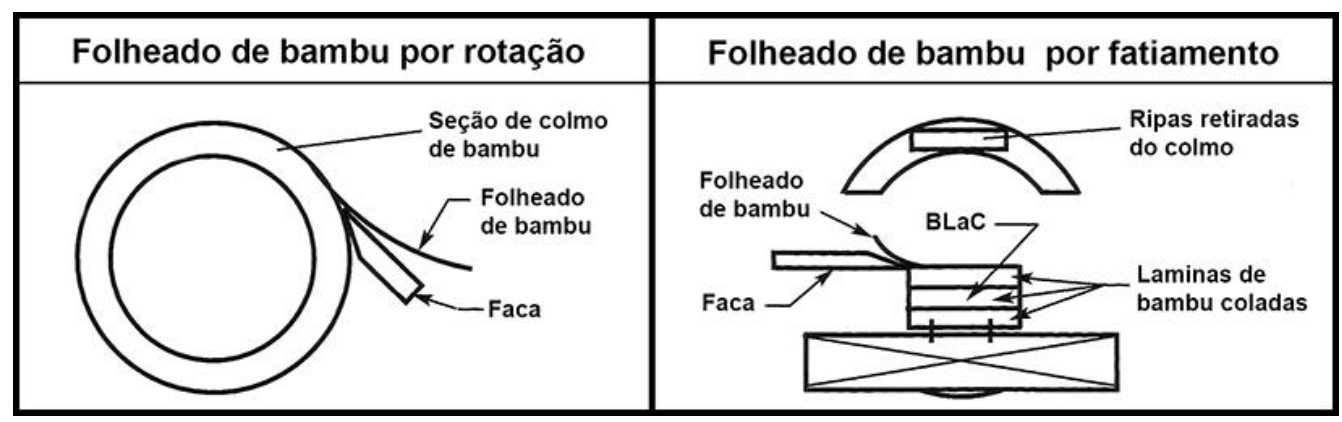

Figura 2 - Obtenção do folheado de bambu por rotação e por fatiamento.

Fonte: adaptado de Hidalgo-López (2003)

Já na técnica de laminação por serragem toda a espessura da parede do colmo é utilizada para produzir ripas mais grossas e planas. Como as lâminas possuem seções pequenas, unindo-se umas as outras é possível se atingir qualquer tamanho ou comprimento. O processamento do bambu em lâminas pode variar dependendo do maquinário e técnica utilizada. Zhaohua (2001) resume as etapas básicas do processo na seguinte ordem: colmos de bambu $\rightarrow$ corte em seções $\rightarrow$ divisão em ripas $\rightarrow$ aplainamento grosseiro $\rightarrow$ fervura $\rightarrow$ secagem $\rightarrow$ aplainamento fino. Já em Xiao, Inoue e Paudel (2008) são apresentadas as etapas da transformação do colmo em ripas laminadas, conforme mostrado na Figura 3.

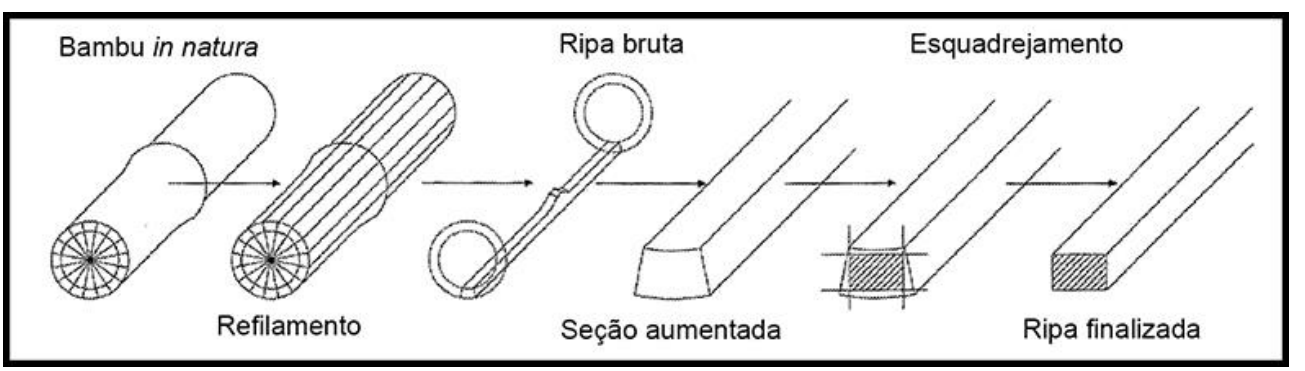

Figura 3 - Etapas do processamento do bambu.

Fonte: adaptado de Xiao, Inoue e Paudel (2008)

Um dos métodos de processamento das lâminas utilizado por Ramos e Pereira (2014), adaptado de Pereira e Beraldo (2008), e de eficiência comprovada, consiste das seguintes etapas: a) desdobro em serra circular destopadeira; b) desdobro em serra 
circular refiladeira dupla; c) imersão das ripas em solução de octaborato de sódio para proteção contra insetos xilófagos; d) secagem; e) beneficiamento inicial das lâminas em serra circular; f) beneficiamento final em plaina duas faces, própria para bambu.

Laminados de bambu são produzidos com ripas de bambu secas e tratadas e que foram aplainadas nos quatro lados. Uma vez que isto é feito, elas são cobertas com adesivo, geralmente à base de ureia-formaldeído em países como a China. Resina de origem vegetal, ou adesivos comuns para madeira como o Acetato de Polivinila (PVA) podem, no entanto, ser também utilizados sem comprometer a resistências dos produtos. Para a aplicação dos adesivos, geralmente são utilizados rolos de pintura, devido a seu baixo preço, eficiência e estabilidade (BINYUAN; JINGYAN, 2001).

Segundo Pereira e Beraldo (2008), estudos desenvolvidos por Rivero (2003) evidenciaram que as características físicas e mecânicas do BLC são plenamente favoráveis ao uso desse material na indústria do mobiliário e de utensílios domésticos. Já Moizés (2007) ressalta que o BLC possui características estruturais e superficiais, portanto é um material, versátil, resistente e aplicável no design de produtos, interiores e construção civil. Talabgaew e Laemlaksakul (2007) e Ventura, Ramos e Pereira (2013) também realizaram estudos que corroboram com as afirmações anteriormente citadas de Pereira e Beraldo e Moizés.

Uma característica apreciada pelos designers ao trabalhar com o bambu laminado, é sua maleabilidade. Ao se aquecer o material a lignina entre as fibras tornase mole, facilitando a curvatura do material em ângulos que só a madeira de Faia (árvores do gênero Fagus) consegue igualar, sendo esta uma das melhores madeiras para curvaturas. Já que o bambu apresenta uma elasticidade linear maior que a madeira, ele quebra com menos facilidade, por isso, a flexibilidade do bambu que pode ser explorada muito bem como vantagem competitiva frente aos produtos de madeira (VAN DER LUGT, 2008).

O BLC utilizado na forma curva, é também conhecido internacionalmente como Parallel Curved Gluelam, é produzido na China e usado para fabricação de mobiliário. As características estéticas das peças curvas de bambu laminado, associadas às possibilidades de formas que podem ser geradas, agregam alto valor a este material na indústria moveleira.

Em seus experimentos, Tejo Remy e René Veenhuizen (apud VAN DER LUGT, 2008) mostraram que finas tiras de Plybamboo (com $3 \mathrm{~mm}$ de espessura) podem até ser curvadas sem aplicação de calor, contanto que as peças sejam fixadas na posição curva final. Remy e Veenhuizen também produziram um protótipo de cadeira com lâminas de bambu encurvadas com vapor (Figura 4). 


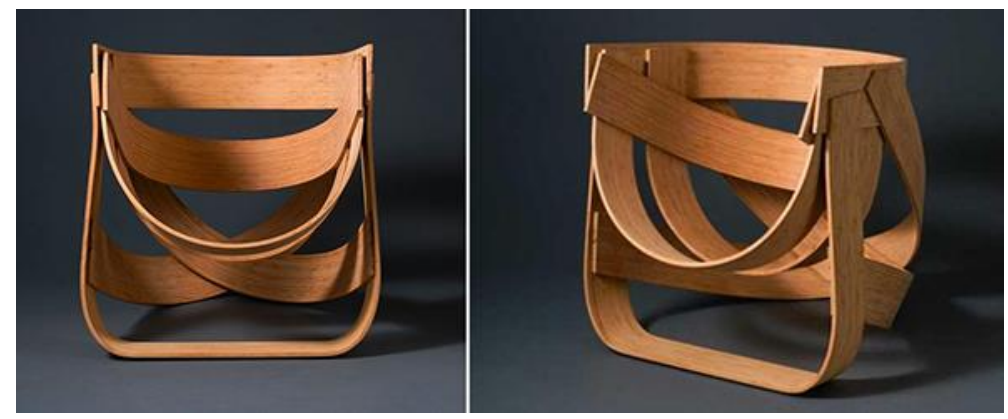

Figura 4 - Protótipo de cadeira de Tejo Remy e René Veenhuizen.

Fonte: Van der Lugt (2008)

No Laboratório de Experimentação com Bambu da UNESP, já foram realizados estudos de mobiliários curvos com BLC, explorando diferentes desenhos de mobiliários e métodos de curvatura do BLC, conforme apresentado a seguir.

Gaion, Paschoarelli e Pereira (2005) desenvolveram um estudo com os objetivos de verificar a possibilidade de desenvolvimento de um produto, concomitantemente à aplicação do bambu laminado e colado da espécie $D$. giganteus como matéria-prima alternativa no design. Os autores descreveram o estudo da seguinte maneira: ripas com largura de $30 \mathrm{~mm}$ foram cortadas com o comprimento de $510 \mathrm{~mm}$ e aparelhadas com uma espessura de $3 \mathrm{~mm}$. Foi desenvolvido um equipamento para curvar as lâminas de bambu que consistiu em um cano de metal submetido ao calor de um maçarico, onde as ripas, em contato com o cano, são aquecidas, facilitando assim a mobilidade e elasticidade de suas fibras. $O$ raio de curvatura obtido com as ripas foi de aproximadamente $50 \mathrm{~mm}$. Após a curvatura, as lâminas foram coladas umas às outras, com adesivo de madeira, até se atingir uma espessura de $30 \mathrm{~mm}$ e finalmente, o conjunto de lâminas foi prensado em um molde e mantido durante $48 \mathrm{~h}$ para cura do adesivo (GAION; PASCHOARELLI; PEREIRA, 2005). A Figura 5 mostra o processo de curvatura das lâminas e o protótipo finalizado.
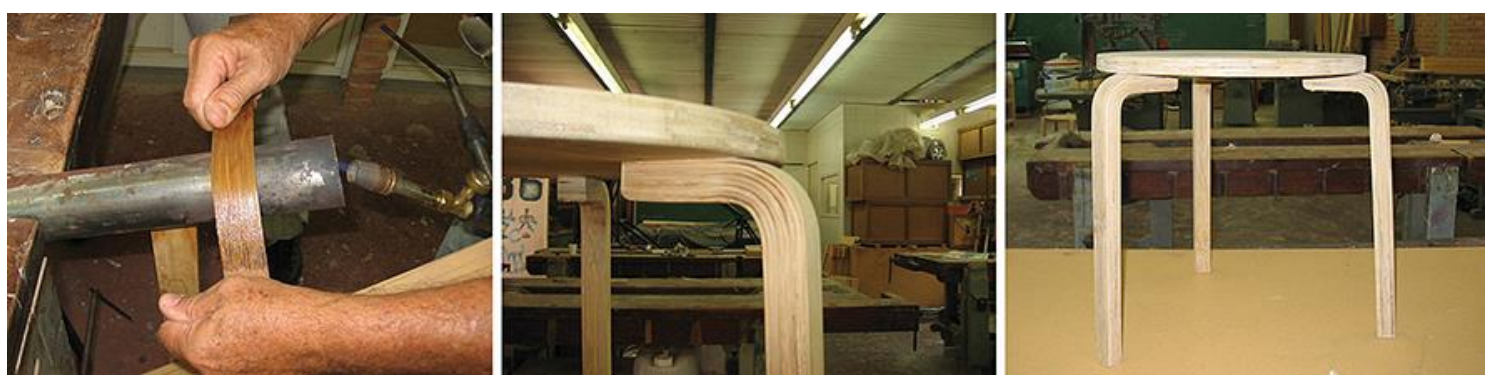

Figura 5 - Curvatura das ripas de bambu e o banco finalizado.

Fonte: Gaion, Paschoarelli e Pereira (2005)

Lourenço e Pereira (2011) apresentaram o projeto e confecção de um protótipo de uma cadeira de lâminas de bambu, utilizando a espécie $D$. giganteus. Para a fabricação do protótipo utilizou-se lâminas de bambu trançadas, assim como se confeccionou um molde aquecido para as colagens e curvaturas das lâminas. $\mathrm{O}$ molde, do tipo macho-fêmea, foi feito com madeira e tiras de alumínio, que são submetidas a altas temperaturas através de um sistema de aquecimento composto por resistências elétricas enroladas em uma pequena chapa de fibras de alta densidade. Algumas etapas do projeto assim como o protótipo finalizado são apresentados na Figura 6. 


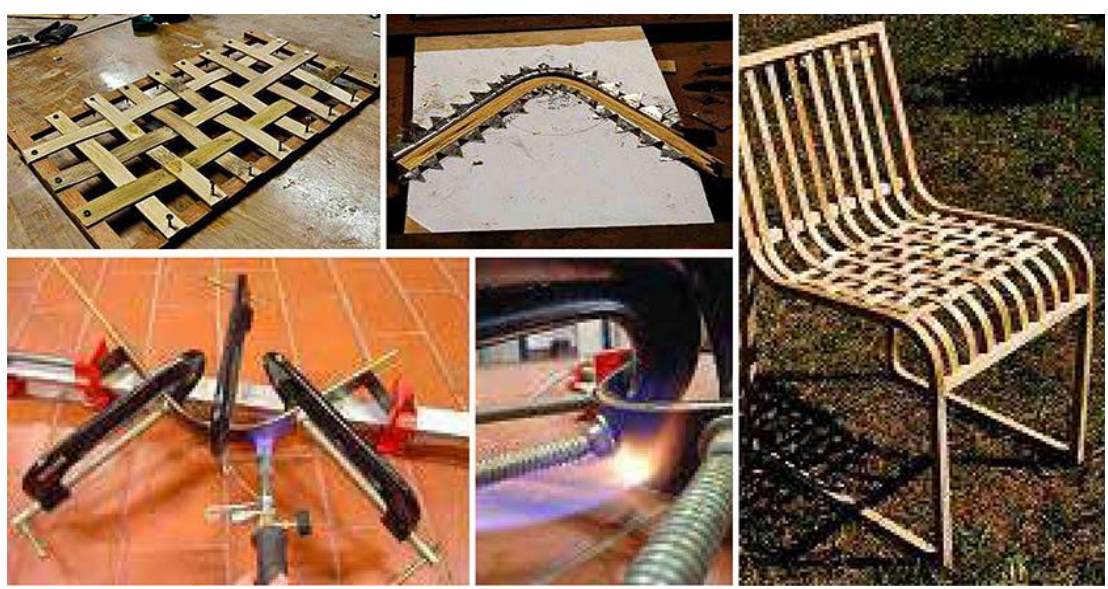

Figura 6 - Etapas do projeto e o protótipo finalizado.

Fonte: adaptado de Lourenço e Pereira (2011)

O projeto de Implantação da Rede Regional de Pesquisa e Desenvolvimento do Bambu, financiado pelo CNPq, teve como parte de seus objetivos aplicar os conhecimentos e tecnologias desenvolvidas na forma de protótipos de mobiliário de chapas de partículas e de BLC, tanto com peças retas, como curvas. Segundo Ramos e Pereira (2014), a confecção do BLC exigiu a colheita de colmos adultos de bambu, da espécie $D$. giganteus, pertencentes à coleção existente no campus da UNESP-Bauru. Com as lâminas de bambu já finalizadas, foram realizadas as colagens e prensagens das mesmas para a confeç̧ão do BLC curvo, por meio de moldes aquecidos. Cada um dos protótipos foi criado com um propósito distinto, sendo que um banco e uma cadeira de descanso foram desenvolvidos para testar formas curvas e orgânicas, que foram passíveis de realização por meio de peças vergadas de BLC obtidas com prensagem em moldes aquecidos, construídos exclusivamente para tal função. A Figura 7 apresenta os moldes desenvolvidos e os dois protótipos finalizados.
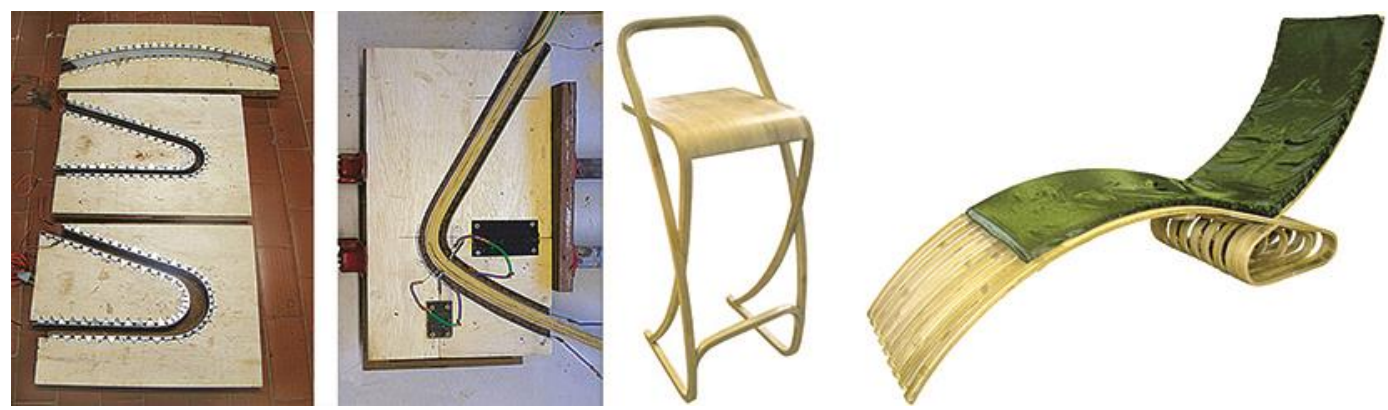

Figura 7 - Moldes e protótipos finalizados.

Fonte: Ramos e Pereira (2014)

No Brasil, em 2008, a empresa ORÉ BRASIL desenvolveu uma linha de móveis em BLC, e segundo Szücs et al. (2010), utilizou, resumidamente, o seguinte processo de fabricação: na serra circular destopadeira os colmos de bambu são seccionados em dimensões já pré-estabelecidas, passando então para a serra circular, onde os colmos são seccionados longitudinalmente, formando taliscas, sendo retiradas as pontas e sobras encontradas na região dos nós. Em seguida, as taliscas são passadas em uma plaina desengrossadeira para que fiquem as mais planas possíveis; seguindo para a plaina de quatro faces, onde são regularizadas suas seções retangulares. Posteriormente as lâminas são levadas para tratamento com ácido pirolenhoso e após 
o tratamento, as lâminas passam novamente na plaina de quatros faces para ficarem com as mesmas espessuras. Por último, é feita a colagem e prensagem das lâminas. A Figura 8 apresenta as lâminas sendo prensadas para uma colagem reta e outra curva, enquanto a Figura 9 mostra dois móveis produzidos pela empresa.
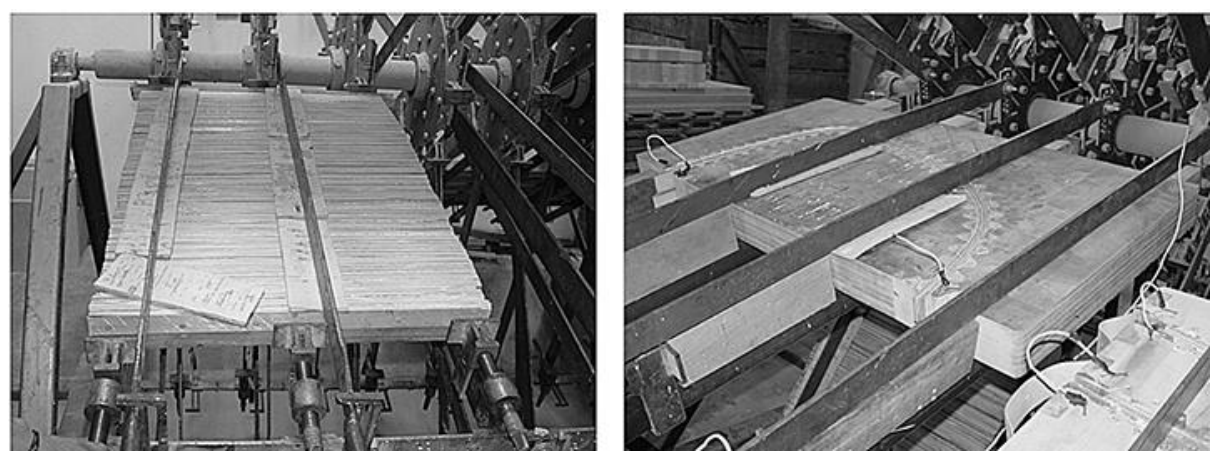

Figura 8 - Lâminas sendo prensadas, após colagem.

Fonte: Szücs et al. (2010)
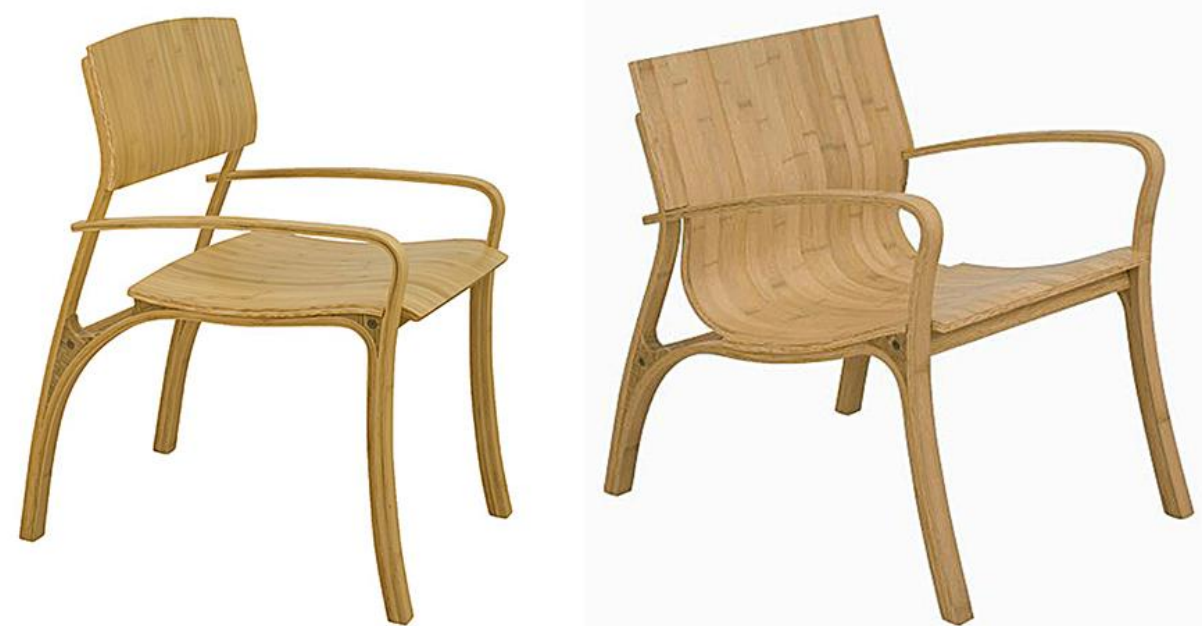

Figura 9 - Móveis em BLC desenvolvidos por Paulo Foggiato para a empresa Oré Brasil.

Fonte: Disponível em: http://c.imguol.com/album/poltronas f 076.jpg e em http://casasemchao.files.wordpress.com/2010/11/cadeira lapa.jpg

\section{CONCLUSÕES}

A escolha do bambu como material de pesquisa se deu pelo fato desta planta apresentar grande potencial como matéria-prima para produtos industriais, e por ser um excelente aliado rumo à sustentabilidade, principalmente à medida que o plantio do bambu e a sua utilização em substituição à madeira, mesmo que seja de reflorestamento, pode evitar o corte de novas árvores e assim diminuir a pressão exercida sobre as florestas, principalmente nativas.

Com a revisão de literatura desenvolvida foi possível reunir informações sobre a planta bambu, suas características e espécies mais adequadas para o uso no bambu laminado colado. Também foram coletadas informações sobre os métodos de processamento do bambu para sua transformação em ripas laminadas, assim como os métodos utilizados para a fabricação do bambu laminado colado, na forma reta e curva. 
Apesar de existir um considerável número de estudos sobre as diversas espécies de bambu e suas características, poucos são os livros, em língua portuguesa, sobre o tema, e em se tratando do BLC, é possível encontrar diversas pesquisas em artigos, dissertações e teses, porém não se tem livros sobre esse assunto em específico, e muito menos sobre técnicas para curvá-lo. Também se constatou uma escassez de trabalhos científicos e de literatura específica sobre curvatura de BLC na língua inglesa.

$\mathrm{Na}$ bibliografia disponível sobre métodos específicos de curvatura de BLC, os poucos trabalhos encontrados são pesquisas de cunho prático ou empírico, não se fundamentando em metodologias anteriormente estudadas, o que justifica a continuidade de pesquisas mais aprofundadas sobre o bambu laminado colado curvo. Entretanto, devido à falta de material sobre a história do bambu laminado e, principalmente, as técnicas utilizadas para a confecção do BLC curvo, torna-se necessário o uso de um material semelhante ao bambu e ao bambu laminado para servir de referência no desenvolvimento da metodologia de curvatura.

Portanto, como etapa seguinte a este trabalho, já está sendo realizada uma revisão de literatura sobre a madeira e a madeira laminada colada, por serem os materiais mais próximos, respectivamente, ao bambu e ao bambu laminado colado. 0 intuito de obter informações mais detalhadas sobre métodos de curvatura que possam ser utilizados com o BLC, embasando de forma mais sólida a pesquisa de mestrado e permitindo a ampliação dos estudos sobre o BLC e sua utilização na confeç̧ão de mobiliário.

\section{REFERÊNCIAS}

BINYUAN, Z.; JINGYAN, J. Transfer of Technology Model (TOTEM): The Bamboo Furniture Making Unit. Nanjing Forestry University, 2001.

CARDOSO JUNIOR, M. L. Recomendações para projeto de piso de Bambu Laminado Colado - BLC. 2008. 163f. Dissertação (Mestrado em Engenharia Ambiental Urbana) Escola Politécnica, Universidade Federal da Bahia, Salvador.

GAION, C. P.; PASCHOARELLI, L. C.; PEREIRA, M. A. R. O bambu como matéria-prima para o design industrial: um estudo de caso. In: CONGRESSO INTERNACIONAL DE PESQUISA EM DESIGN, 3. 2005, Rio de Janeiro. Anais do 3ㅇ Congresso Internacional de Pesquisa em Design, Rio de Janeiro, ANPED, 2005.

GRECO, T. M.; CROMBERG, M. Bambu: cultivo e manejo. Florianópolis: Editora Insular, 2011.

HIDALGO-LÓPEZ, O. Bamboo the gift of the gods. D'Vinni Ltda: Bogotá, 2003.

LOURENÇO, M.; PEREIRA, M. A. R. Desenvolvimento de mobiliário em bambu laminado sob os conceitos de ecodesign. In: SIMPÓSIO PARANAENSE DE DESIGN SUSTENTÁVEL, 3. 2011, Londrina. Anais do $3^{\circ}$ Simpósio Paranaense de Design Sustentável, Londrina, UEL, 2011. P. 83-93.

MOIZÉS, F. A. Painéis de bambu, uso e aplicações: uma experiência didática nos cursos de Design em Bauru, São Paulo. 2007. 113f. Dissertação (Mestrado em Design) Faculdade de Arquitetura, Artes e Comunicação, Universidade Estadual Paulista Júlio de Mesquita Filho. 
PEIXOTO, L. K. O potencial construtivo do bambu e as vantagens do laminado colado a partir deste insumo. In: SEMINÁRIO NACIONAL DA REDE BRASILEIRA DO BAMBU, 2. 2010, Rio Branco. Anais do 20 Seminário Nacional da Rede Brasileira do Bambu, Rio Branco, 2010. P. 129-142.

PEREIRA, M. A. R.; BERALDO, A. L. Bambu de corpo e alma. Bauru: Editora Canal 6, 2008. RAMOS, B. P. F.; PEREIRA, M. A. R. O Uso do Bambu Laminado Colado na Confecção de Mobiliário. Revista Estudos em Design, Rio de Janeiro, RJ, v.22.1, abr. 2014.

RAO, A. N.; RAO, V. R.; WILLIAMS, J. T. (Org.). Priority Species of Bamboo and Rattan. INBAR Technical Report, Serdang, n.1, 1998.

REUBENS, R. Bamboo in Sustainable Contemporary Design. INBAR Working Paper, Beijing, n.60, 2010.

RIVERO, L. A. Laminado colado e contraplacado de bambu. 2003. 99f. Dissertação (Mestrado em Construções Rurais e Ambiência) - Faculdade de Engenharia Agrícola, Universidade Estadual de Campinas.

SZÜCS, C. A. et. al. Bambu laminado colado para fabricação de móveis em Santa Catarina. In: SEMINÁRIO NACIONAL DA REDE BRASILEIRA DO BAMBU, 2. 2010, Rio Branco. Anais do 2 Seminário Nacional da Rede Brasileira do Bambu, Rio Branco, 2010. P. 143-154.

TALABGAEW, S.; LAEMLAKSAKUL, V. Experimental Studies on the Mechanical Property of Laminated Bamboo in Thailand. World Academy of Science, Engineering and Technology, n.34, 2007.

VAN DER LUGT, P. Design Interventions for Stimulating Bamboo Commercialization: Dutch Design meets Bamboo as a Replicable Model. Delft: VSSD, 2008.

VAN DER LUGT, P; VOGTLÄNDER, J.; BREZET, H. Bamboo, a Sustainable Solution for Western Europe: Design Cases, LCAs and Land-use. INBAR Technical Report, Beijing, n.30, 2009.

VENTURA, F. C.; RAMOS, B. P. F.; PEREIRA, M. A. R. Verificação de aplicabilidade do adesivo de óleo de mamona na confecção de bambu laminado colado. In: INTERNATIONAL WORKSHOP - ADVANCES IN CLEANER PRODUCTION, 4. 2013, São Paulo. Anais do 4th International Workshop - Advances in Cleaner Production, São Paulo, UNIP, 2013.

XIAO Y.; INOUE M.; PAUDEL S. K. (Org.). Modern bamboo structures. Boca Raton: CRC Press, 2008.

YUMING, Y.; CHAOMAO, H. China's Bamboo: culture / resources / cultivation / utilization. INBAR Technical Report, Beijing, n.33, 2010.

ZHAOHUA, Z. Sustainable Development of the Bamboo and Rattan Sectors in Tropical China. INBAR Proceedings, Beijing, n.6, 2001.

AGRADECIMENTOS

À CAPES e ao PPG Design da Unesp de Bauru, pela bolsa de pesquisa de mestrado. 